\title{
COMMENTARY
}

\section{Osteopathic Principles and Practice:}

\section{Essential Training for the Primary Care Physician of Today and Tomorrow}

\author{
Saroj Misra, DO
}

(Fam Med. 2021;53(7):544-7.)

doi: 10.22454/FamMed.2021.123494

Published Online First June 15, 2021

0 steopathic medicine's long history is deeply woven into the fabric of primary care in the United States. Since its humble beginnings in 1892 to its current training scope, involving over 150,000 doctors of osteopathy (DOs) and osteopathic medical students training at 38 colleges of osteopathic medicine in the United States, ${ }^{1}$ the osteopathic profession has increased exponentially within the larger context of medical care. Today's modern landscape of both practice and training has seen osteopathic trainees and physicians work alongside their allopathic counterparts in every discipline in a collegial and coordinated manner. Single accreditation has created a new paradigm that has unified oversight of all residency training under one organization with initial success, and the logical next step is to integrate osteopathic training for all graduate medical education to better serve patients and society.

The implications of single accreditation for the osteopathic educational community have been far-reaching with second and third-order considerations. Obvious outcomes of this process were the acknowledgement of osteopathy within the overall competency-based educational framework of Core Competencies and Milestones. The American Council for Graduate Medical Education (ACGME), working in conjunction with the American Osteopathic Association (AOA) and its educational member affiliates, recognized that osteopathy must continue to meet the needs of physicians, faculty, residents, and students who ascribe to and practice osteopathy on behalf of society. Furthermore, it was recognized that traditionally osteopathic-centered programs often have distinctive components and qualities that are unique to training, both from an aspirational and practical perspective. The immediate solution was to create the designation of "Osteopathic Recognition" to identify those programs that have chosen to continue (or newly take up) osteopathic training elements. Osteopathic recognition has been seen as critically important to the continuation of osteopathically distinct training for all invested stakeholders. The most recent data shows that Osteopathic Recognition has been an important designation for programs, with over 230 programs receiving this designation and another 220+ seeking it (accounting for $5 \%$ of all accredited residency training programs). Of these programs, almost two-thirds of them are in the discipline of family medicine, accounting for over $20 \%$ of all accredited family medicine programs in the United States. ${ }^{2}$

While Osteopathic Recognition has seen strong uptake within family medicine, many opportunities still exist to better cement osteopathy within the larger scheme of graduate medical education. To do this, we must ask and answer the critical question, "How does osteopathy as a distinct approach to medical care fit into the larger training framework established by the ACGME?" This has necessitated an examination of the essence of osteopathic medicine and how its value be identified for residency training and ultimately patient care. It is important to recognize that osteopathic

From the American College of Osteopathic Family Physicians, Arlington Heights, IL. 
medicine most clearly flows from the four osteopathic tenets that are central to the definition of osteopathy. These tenets, codified by Dr Andrew Taylor Still, are universal amongst osteopaths today and drive osteopathic approaches to patient care. They identify that a person's health and illness have physical, psychologic, and spiritual/emotional components, that the body's function and structure are intrinsically linked, and that the body can self-regulate and self-heal. Unlike other elements of osteopathic medicine (notably naming terminology for specific somatic dysfunctions and their relevant techniques), there is very little debate about these tenets or their wording, resulting in a universal adoption of them as unchanging elements of osteopathic medicine that define osteopathic principles and practice. ${ }^{3}$ These tenets also help to identify guiding concepts for the practice of medicine, not just osteopathically, but for all practitioners. By considering what practical applications flow from these tenets, we can see that they represent cognitive approaches to diagnosis (eg, the presence of disease is the result of self-regulation gone awry; correcting such mechanisms can lead to normalization of the patient), considerations of specific treatment options (eg, physical manipulation of structure can lead to functional improvements of different physiologic elements), and holistic approaches when considering the overall patient experience (eg, considering psychological and emotional ramifications of both disease and treatment options).

The value of osteopathic principles is not simply aspirational or theoretical. The ability to manage patients' real physical concerns using distinct osteopathic techniques is an essential element of comprehensive patient care and a valuable tool for the general population. Consider, for example, musculoskeletal complaints, which are present in as much as $48 \%$ of the population, ${ }^{4}$ account for as much as $3.4 \%-5.8 \%$ of the US gross domestic profit ${ }^{5}$ and are the second-most reported reason patients see primary care physicians (PCPs) ${ }^{6}$ Osteopathic manipulative technique (OMT) has been shown to effectively treat many conditions such as low back pain with a reduced cost and need for concomitant medication use or medical intervention. ${ }^{7}$

The osteopathic approach to caring for the patient predicates more than just simple technique. Rather, it suggests elements germane to all care provided by all_practitioners for any patient. Osteopathy provides a rubric within its templates to combat the fragmentation of care phenomenon that has dominated the practice of medicine for the last three decades. As noted in the literature, successful strategies to combatting fragmentation include a patientcentered approach that identifies both physical comfort and emotional well-being as top priorities. ${ }^{8}$ Other sources identify aspects of osteopathic tenets (such as helping patients with the mental and socioemotional components of active health care and reducing dependency on specialist-centered care) in solutions to this problem. ${ }^{9}$

As we move forward and consider how graduate medical education has successfully integrated traditionally osteopathic training programs into the larger framework of unified evaluation and assessment through Core Competencies, Milestones and Entrustable Professional Activities, we should equally begin to consider how the distinct osteopathic tenets have value for all clinical trainees, and that integrating these universally across training programs would benefit not only learners, but patients. Primary integration should be focused on attentiveness to the tenets themselves, for reasons postulated above, while secondary integration can be focused on specific modalities of treatment (such as osteopathic manipulative medicine) for those who are willing to learn and apply it. Osteopathic medicine (especially OMT) has been taught to MDs and allopathic residents for years within dual-accredited programs where MD and DO residents learned side-by-side and through focused workshops that have been provided for decades by institutions such as Harvard Medical School and the Michigan State University College of Osteopathic Medicine..$^{10}$ More recently, longitudinal curricula designed specifically to teach OMT to allopathic residents have been developed and found to be effective. ${ }^{11}$

By acknowledging the universality of osteopathic tenets in the overall care of society, we recognize the intrinsic value of keeping these ideas at the forefront of medical education and practice. Encoding it within the framework of teaching and training environments in an integrated fashion (Figure 1) ensures that tomorrow's doctors will be able to manage patients' needs in a collaborative and holistic approach that is better aligned with the idea of first doing no harm, and second, ensuring that we prioritize the human behind the conditions we treat. It is clear that osteopathic principles are not just for osteopaths; they are for everybody who holds these goals as primary points of focus. 
Figure 1: Sample of Osteopathic Principles Integrated Into Core Competencies for Resident Assessment

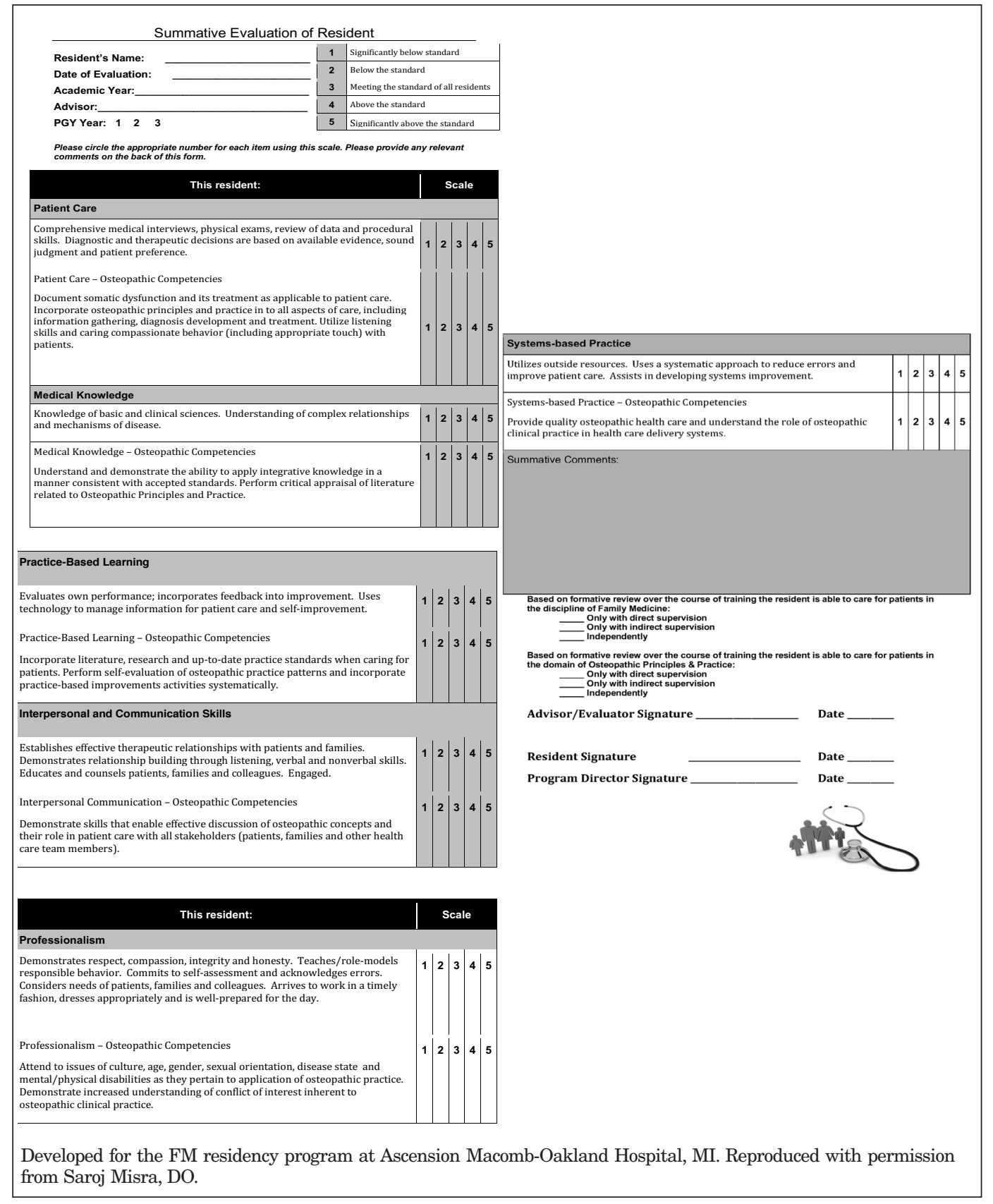

CORRESPONDENCE: Address correspondence to Dr Saroj Misra, American College of Osteopathic Family Physicians, 330 E. Algonquin Road, Suite 1 Arlington Heights, IL 60005. sarojm@mac.com.

\section{References}

1. Osteopathic Medical Profession Report, 2019. Chicago, American Osteopathic Association; 2020. https://osteopathic.org/wp-content/uploads/OMP2019-Report_Web_FINAL. pdf. Accessed May 3, 2021.
2. Data Resource Book Academic Year 2019-2020. Chicago: Accreditation Council for Graduate Medical Education; 2020. https://www.acgme.org/About-Us/Publications-andResources/Graduate-Medical-Education-Data-ResourceBook. Accessed May 3, 2021.

3. Tenets of Osteopathic Medicine. Chicago: American Osteopathic Association. https://osteopathic.org/ about/leadership/aoa-governance-documents/tenetsof-osteopathic-medicine/. Accessed January 25, 2021. 
4. Hagen K, Linde M, Heuch I, Stovner LJ, Zwart JA. Increasing prevalence of chronic musculoskeletal complaints. A large 11-year follow-up in the general population (HUNT 2 and 3). Pain Med. 2011;12(11):1657-1666. doi:10.1111 j.1526-4637.2011.01240.x

5. Lezin N, Watkins-Castillo S. The hidden impact of musculoskeletal disease on Americans. Rosemont, IL: Bone and Joint Initiative USA; 2018. https://www.boneandjointburden.org/docs/BMUS\%20Impact\%20of\%20MSK\%20on $\% 20$ Americans\%20booklet_4th\%20Edition\%20\%282018\%29. pdf. Accessed May 3, 2021.

6. Finley CR, Chan DS, Garrison S, et al. What are the most common conditions in primary care? Systematic review. Can Fam Physician. 2018;64(11):832-840.

7. Licciardone JC, Brimhall AK, King LN. Osteopathic manipulative treatment for low back pain: a systematic review and meta-analysis of randomized controlled trials. BMC Musculoskelet Disord. 2005;6(1):43. doi:10.1186/1471-24746-43
8. What is Patient-Centered Care? NEJM Catalyst. Published January 1, 2017. https://catalyst.nejm.org/doi/ full/10.1056/CAT.17.0559. Accessed March 10, 2021.

9. Mate KS, Compton-Phillips AL. The Antidote to Fragmented Health Care. Harvard Business Review. Published December 15, 2014. https://hbr.org/2014/12/the-antidote-tofragmented-health-care. Accessed March 10, 2021.

10. Schierhorn K. Helping hands? DOs make case for teaching MDs OMT basics. The DO. Published June 5, 2013. https:// thedo.osteopathic.org/2013/06/helping-hands-dos-makecase-for-teaching-mds-omt-basics/. Accessed March 10, 2021.

11. Dubey J, James S, Zakletskaia L. Osteopathic manipulative treatment for allopathic physicians: piloting a longitudinal curriculum. J Osteopath Med. $2021 \mathrm{Feb}$ 15;121(4):371-376. doi: 10.1515/jom-2020-0038. 